\title{
SYNDROMAL CHARACTERISTICS OF THE COMBINED COURSE OF CHRONIC PANCREATITIS AND ARTERIAL HYPERTENSION
}

DOI: $10.36740 /$ WLek202003103

\author{
Ksenija I. Chubirko', Olesya M. Horlenko', Tetiana M. Bentsa' ${ }^{2}$, Mariia A. Derbak', Adrian I. Tomey', \\ Gabriella B. Kossey ${ }^{1}$, Lyubov Yu. Pushkash' ${ }^{1}$, Valeriya V. Brych ${ }^{1}$, Ivan I. Pushkash ${ }^{1}$ \\ 'SHEI «UZHHOROD NATIONAL UNIVERSITY», UZHHOROD, UKRAINE \\ 25HUPYK NATIONAL MEDICAL ACADEMY OF POSTGRADUATE EDUCATION, KYIV, UKRAINE
}

\begin{abstract}
The aim:To study the clinical course of chronic pancreatitis (CP) in patients with concomitant hypertension.

Materials and methods: A thorough analysis of the results of subjective and clinical and laboratory examinations of 102 patients with $\mathrm{CP}$, who were hospitalized in the therapeutic department of Khust district hospital during 2017-2018 was conducted.

Results: Takingintoaccount that the initial examination of patients was carried out during the period of exacerbation of the disease, all patients presentedwith pain syndrome (100\%).The overwhelming majority of patients identified pain as permanent aching discomfort in the abdominal cavity with periodic intensification $(n=41(40,2 \%), 18$ patients indicated burning pain $(17,6 \%), 30$ - cutting $(29,4 \%)$ ), and $13(12,7 \%)$ experienced pain of varying nature.due to the presence of hypertension (GC) 73 (71.6\%) patients complained of a headache of a paroxysmal periodic pulsating character, which was most often localized in the occipital-frontal area and was accompanied by dizziness, "flickering of flies" before the eyes, noise in the ears. Also, 14 (13,7\%) patients had shortness of breath at moderate physical exercise, lower extremity edema that appeared in the afternoon and disappeared by the morning.In addition, $33(32,4 \%)$ surveyed patients indicated a periodic heartbeat.In $18(17,7 \%)$ patients sporadic dizziness was observed. The level of blood pressure (BP), which was established in the studied patients, corresponded to arterial hypertension of grade 1-2 (154,15 $\pm 9,24 / 94,53 \pm 9,05 \mathrm{~mm} \mathrm{Hg})$. In terms of heart rate (HR) in the examined patients, it was $80.26 \pm 10.73$ beats per minute.

Conclusions: According to the study, the negative impact of concomitant hypertension on the clinical course of chronic pancreatitis was established, namely: hypertension in most cases causes intensification of pain syndrome; pain syndrome in comorbid patients with cronic pancreatitis and arterial hypertension is accompanied by more pronounced manifestations of asthenisation: general weakness, lethargy;dependence of the duration of pain syndrome from the height of blood pressure and the duration of arterial hypertension was found; dyspepsia syndrome is more pronounced, varied and prolonged in patients with high blood pressure; smoking (37,3\%), alcohol (19,6\%), psychoemotional overload (6,9\%) are common etiologic factors in comorbid patients with chronic pancreatitis and arterial hypertension; BMI results indicate the dominance of excess body mass in most comorbid patients with chronic pancreatitis and arterial hypertension.
\end{abstract}

KEY WORDS: chronic pancreatitis, arterial hypertension, course

Wiad Lek. 2020;73(3):428-433

\section{INTRODUCTION}

The significant advances made in modern diagnostics and pharmacotherapy have not solved the problem of chronic pancreatitis (CP), which remains one of the most difficult sections not only of pancreatology, but also of clinical gastroenterology in general. Prevalence, increase in morbidity of chronic pancreatitis, temporary disability and cause of disability is relevant both from social and economic point of view, which is confirmed by the data of epidemiological analysis $[1,2]$.

Features of clinical course of chronic pancreatitis are often determined by its combination with other diseases in conditions of polymorbidity of the modern patient. Such combinations, as a rule, contribute to greater torpidity of the clinical course of pancreatitis and often increased number of complications $[1,2,3]$.

In the studies of T. I. Vyun (2015) it is noted that in most cases $(73,7 \%)$ chronic pancreatitis preceded the formation of hypertension (GC), in $18,4 \%$ of patients arterial hypertension developed earlier; $7,9 \%$ of patients could not indicate which pathology occurred first. Clinical course of chronic pancreatitis in patients with hypertension, compared with patients with isolated form of chronic pancreatitis, was characterized by greater severity of abdominal pain syndrome with a tendency to longer exacerbations (3-4 weeks and 10-12 days, respectively).Lower efficacy of pain syndrome therapy was noted: the clinical effect was reached after 9-10 days and 6-7 days, respectively. According to the author's conclusions, the peculiarities of the clinical course of chronic pancreatitis are often determined by its combination with other diseases in the conditions of polymorphism of the modern patient, which is an indication for the expansion of therapy $[4,5]$.

According to I.G. Pakhomova (2003), the recurrent form of chronic pancreatitis combined with arterial hypertension, compared with the isolated form of the 
disease, is characterized by a more severe clinical course: greater severity of abdominal pain syndrome and dyspeptic syndromes with a tendency for longer exacerbations and lower efficacy of basic therapy. At the same time, in patients with an isolated form of CP, the causes of exacerbation are usually errors in the diet $(53,13 \%)$ and/or alcohol intake $(18,75 \%)$. On the contrary, in patients with chronic pancreatitis combined with GC, occurrence of these factors is significantly lower $(44,4 \%$ and $11,15 \%$, respectively), whereas psycho-emotional overload $(19,05 \%)$ and physical stress have a greater role in the structure of exacerbations $(11,15 \%)$ [1].

Analysis of the data presented in scientific sources allows us to assert that the features of clinical manifestations of chronic pancreatitis when combined with arterial hypertension have not been sufficiently investigated, which justifies the need for further in-depth studies of the features of the course of chronic pancreatitis in combination with arterial hypertension.

\section{THE AIM}

To determine the clinical course of chronic pancreatitis in patients with concomitant arterial hypertension.

\section{MATERIALS AND METHODS}

In order to evaluate the clinical course of chronic pancreatitis in combination with arterial hypertension, we conducted a thorough analysis of the results of subjective and clinical and laboratory examinations of 102 patients with chronic pancreatitis, who were hospitalized in the therapeutic department of Khust district hospital during 2017-2018. The average age of the surveyed patients was $51 \pm 10$ years. The gender distribution revealed a slight predominance of female patients (56\%) compared to male patients (44\%). The average duration of chronic pancreatic injury ranged from 4 to 10 years.

Diagnosis of chronic pancreatitis was verified on the basis of medical history data, clinical manifestations and results of laboratory and instrumental studies. Assessment of blood pressure was based on the basic requirements of the «Unified Clinical Protocol for Primary, Emergency and Secondary (Specialized) Medical Assistance to Hypertension», approved by the order of the Ministry of Health of Ukraine No. 384 of May 24, 2012, on Clinical Recommendations for Arterial Hypertension of the EuropeanSocietyofHypertension (ESH) and the European Society of Cardiology (EuropeanSocietyofCardiology (ESC) (2013 and 2018).

Pain intensity was assessed according to a 10-point visual-analogue pain scale (J. J. Bonica, 1990). [6].

\section{RESULTS}

To evaluate the clinical course of chronic pancreatitis in combination with arterial hypertension, we conducted a thorough analysis of the results of subjective and objective examinations. Taking into account that the initial examination of patients was carried out during the period of exacerbation of the disease, all patients had pain syndrome (100\%). Regarding the localization of pain, the majority (71 patients $-69,6 \%$ ) indicated pain in the epigastric region, 31 patients $(30,4 \%)$ - in the left hypochondrium. The irradiation of pain was multidirectional.

The overwhelming majority of patients identified pain as permanent aching discomfort in the abdominal cavity with periodic intensification $(n=41(40,2 \%), 18$ patients indicated burning pain (17,6\%), 30 - cutting (29.4\%)), and $13(12.7 \%)$ experienced pain of varying nature, in addition, it is important to note that periodic pain was observed in 53 patients $(51,9 \%)$ and permanent pain in $49(48,1 \%)$. According to the data obtained, it was found that low-intensity pain sensations (within 1 to 3 points) were not reported by any of the patients. Medium intensity pain (4-6 points) was found in the majority of patients with exacerbation of chronic pancreatitis $(n=55 ; 53,9 \%)$, pain sensations of pronounced intensity (7-9 points) were recorded in 47 patients $(46,1 \%$.) A pain score of 10 was not found in any of the completed questionnaires.

A statistically significant direct correlation of moderate strength between pain level and a1-AT concentration $(\mathrm{r}=$ $0,40 ; p<0,01)$ and urine diastase level $(r=0,45 ; p<0,01)$ was recorded. Significant positive weak association with blood lipase $(r=0,25 ; p=0,01)$, amylase $(r=0,27 ; p=$ $0,006)$ levels was established. The intensity of pain was also variable (Fig. 1).

According to the data obtained, it was found that patients with poor intensity pain syndrome (within 1 to 3 points) were not observed in the study sample. Medium intensity pain (4-6 points) was found in the majority of patients with exacerbation of chronic pancreatitis $(n=55 ; 53,9 \%)$, pain sensations of pronounced intensity (7-9 points) were recorded in 47 patients $(46,1 \%)$. A score of 10 points was not detected in any of the completed questionnaires. Identification of statistically significant weak correlation of negative direction between the severity of pain, according to the indicators of the visual-analogue scale, and the duration of chronic pancreatitis $(r=-0,27, p=0,03)$ was an important element of the study.This information is in line with the opinion of the majority of scientists who confirm the decrease in the intensity of abdominal pain in the process of disease progression, which can be explained by the progressive fibrosis of the pancreatic parenchyma. Pain of low intensity (1-3 points) and pain score of 10 points were not determined in any patient.

In the processof analysis of the dependence of pain on the laboratory parameters studied by us correlation relationships of different strength and direction were established.The dependence of pain on the functional capacity of the pancreas is of interest. Reliable direct correlation of moderate strength between the pain level and a1-AT concentration $(r=0,40, p<0,01)$ and urine diastase level $(r=0,45, p<0,01)$ was recorded.Significant positive weak association between bloodlipase $(\mathrm{r}=0.25, \mathrm{p}=0,01)$, amylase $(r=0,27, p=0,006)$ levels was found. No statistically 


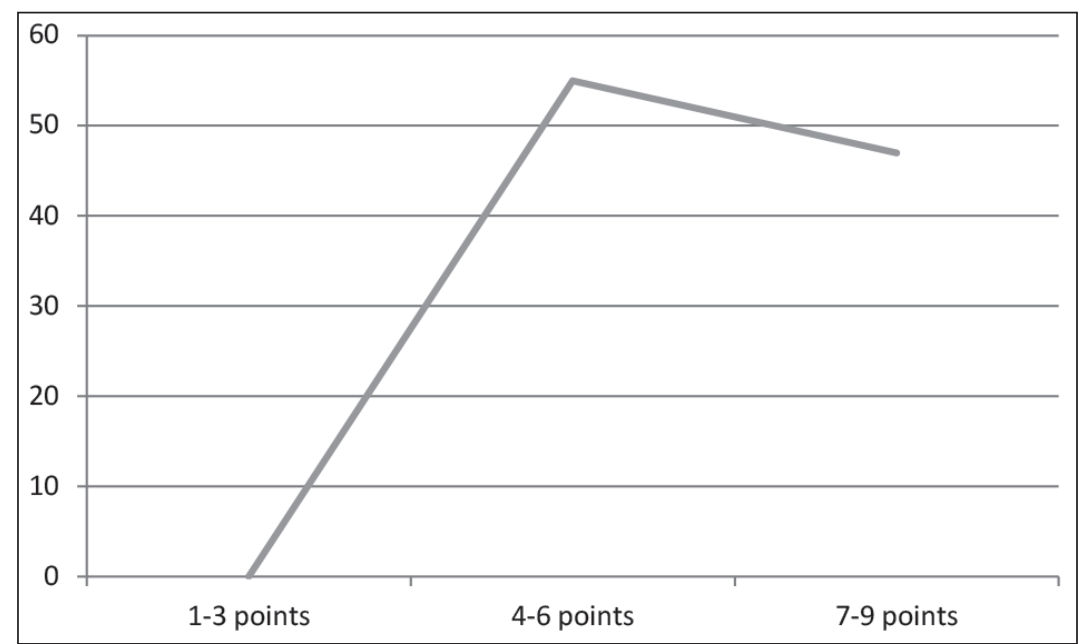

Figure 1.The intensity of pain

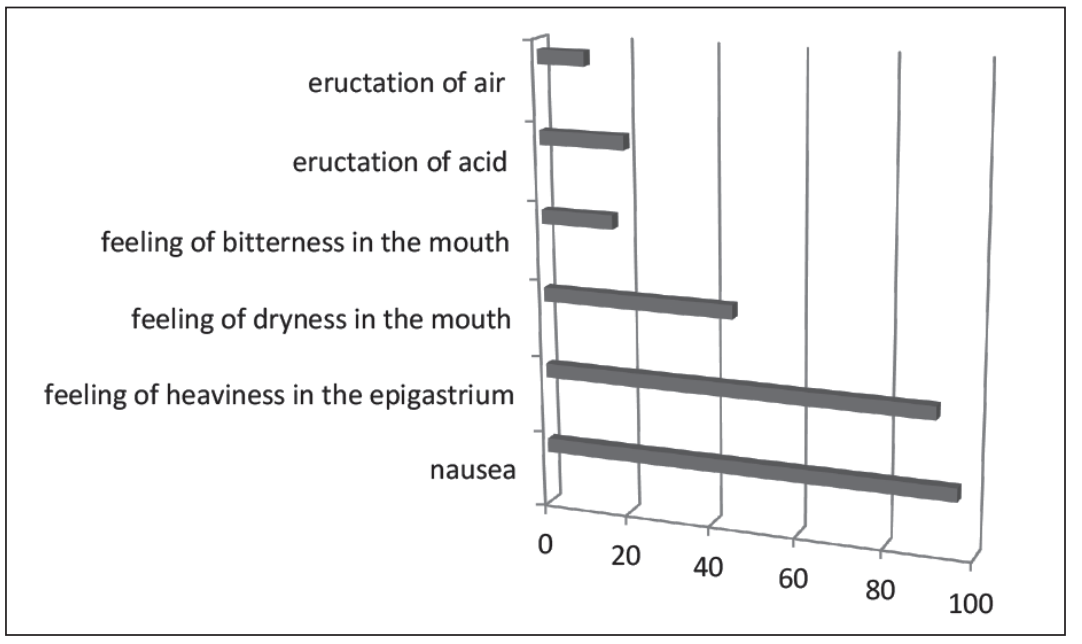

Figure2. Symptoms of the dyspeptic syndrome

significant correlation was found between pain intensity and elastase- 1 content in feces. Among the indicators of inflammatory response of the organism a reliable direct modaratestrength correlation between the intensity of pain and the level of leukocytes $(r=0,51, p<0,01)$, neutrophils $(\mathrm{r}=0,42, \mathrm{p}<0,01)$, ESR $(\mathrm{r}=0.54, \mathrm{p}<0.01)$ was revealed. A significant positive weak correlation between pain intensity and fibrinogen $(\mathrm{r}=0,25, \mathrm{p}=0,01)$ and cortisol $(\mathrm{r}=0,21$, $\mathrm{p}=0,04)$ levels was found.

When searching for factors that contributed to the activation of pain, it was found that 57 patients $(55,9 \%)$ indicated an increase in pain after eating, especially fried, smoked, fatty food (10,7\%), freshly baked bakery products, carbonated beverages, semi-finished products.According to the data obtained, 27 patients $(26,5 \%)$ had sitophobia.In addition, patients noted increased pain in supine position $(\mathrm{n}=81 ; 79,4 \%)$ and with change of body position $(\mathrm{n}=37$; 36,3\%).Pain was somewhat relieved in sitting position while leaning forward and being on the left side in a horizontal position with legs lowered to the torso.In addition, to reduce pain, some patients $(n=27 ; 26,4 \%)$ used antispasmodics, analgesics and/or enzyme preparations, but the use drugs mentionedabovedidnot give lasting effect, what eventually forced patients to seek specialized medical care.Patients experienced a predominance of pain syndrome over others, but dyspeptic syndrome and external secretory pancreatic insufficiency syndrome also played a major role in the patients' well-being.Analyzing the relationship between the level of pain and the components of antioxidant protection, we found a significant positive moderate strength correlation with the level of urea $(r=0,44 ; \mathrm{p}<0,01)$ and bilirubin $(\mathrm{r}=$ $0.41 ; \mathrm{p}<0.01$ ).Among the indicators of lipid metabolism, pain was correlated with the concentration of LDL cholester$\mathrm{ol}(\mathrm{r}=0,20 ; \mathrm{p}=0,04)$, HDL cholesterol $(\mathrm{r}=-0,27 ; \mathrm{p}=0,01)$ and Apo B $(r=0,21 ; p=0,03)$. The relationship between pain intensity and heart rate was found to be natural $(\mathrm{r}=$ 0,$27 ; p=0,01$ ). Patients experienced a predominance of pain syndrome over others, but dyspeptic syndrome and external secretory pancreatic insufficiency syndrome also played a major role in altering patients' well-being. Dyspeptic syndrome was manifested by the following complaints: nausea, vomiting, feeling of heaviness in the epigastrium, belching, and decreased appetite(Fig. 2).

Nausea, which was indicated by $96(94,1 \%)$ patients appeared to be the leading symptom of the syndrome mentioned above in the surveyed contingent.Nausea 
Table I. Blood pressure level and heart rate in the studied patients

\begin{tabular}{cc}
\hline Parameters & Blood pressure level $(\mathbf{M} \pm \mathbf{m})$ \\
\hline Systolic blood pressure $(\mathrm{mm} \mathrm{Hg})$ & $154,15 \pm 9,24$ \\
\hline Diastolic blood pressure $(\mathrm{mm} \mathrm{Hg})$ & $94,53 \pm 9,05$ \\
\hline Pulse pressure $(\mathrm{mm} \mathrm{Hg})$ & $59,62 \pm 11,52$ \\
\hline Heart rate (beats/minute) & $80,26 \pm 10,73$ \\
\hline
\end{tabular}

Table II. Trophological characteristics of the examined contingent of comorbid patients

\begin{tabular}{ccc}
\hline BMI $\left(\mathbf{k g} / \mathbf{m}^{\mathbf{2}}\right)$ & $\begin{array}{c}\text { Absolute number } \\
(\mathbf{n = 1 0 2})\end{array}$ & $\%$ \\
\hline$<18,5$ & 2 & 2 \\
\hline $20,0-24,9$ & 29 & 28,4 \\
\hline $25,0-29,9$ & 48 & 47,1 \\
\hline $30,0-34,9$ & 19 & 18,6 \\
\hline $35,0-39,9$ & 3 & 2,9 \\
\hline$>40$ & 1 & 1 \\
\hline
\end{tabular}

of paroxysmal periodicity statistically significantly outweighed the constant nausea $(\mathrm{n}=74(72,5 \%)$ versus $\mathrm{n}=$ $28(27,5 \%), \mathrm{p}<0,01)$, appearance of which was facilitated by the consumption of food and alcohol.Some patients ( $\mathrm{n}$ $=48 ; 47,1 \%)$ had vomiting that did not alleviate the overall condition. The sensation of heaviness in the abdominal cavity was determined in $91(89,2 \%)$ of the surveyed patients. Again, the latter sensations intensified after food consumption, forceing patients to limit the frequency and number of intake.Patients also complained of belching of different character. Most often, patients indicated eructation of acid $(\mathrm{n}=20 ; 19,6 \%)$ and air $(\mathrm{n}=11 ; 10,7 \%)$. In 17 patients (16,7\%), a feeling of bitterness and in 45 (44.1\%) dryness in the oral cavity was identified.

As with any inflammatory process, and in the case of exacerbation of chronic pancreatitis in combination with arterial hzpertension, there was a pronounced asthenovegetative syndrome, which manifested as general weakness, rapid fatiguability, drowsiness, dysomnia, increased irritability. General weakness, impaired performance, and rapid fatiguability of varying degrees were present in all patients. Excessive drowsiness was identified in $95(93,1 \%)$ patients, sleep disorders in $43(42,2 \%)$, and increased irritability in $56(54,9 \%)$ patients.

Furthermore, due to the presence of arterial hypertension in $73(71,6 \%)$ patients, there were complaints of headache with paroxysmal periodic pulsatile character, which was most often localized in the occipital-frontal area and was accompanied by dizziness, "flickering of flies» in the eyes, noise in the ears. Additionally, $14(13,7 \%)$ patients had shortness of breath at moderate physical exercise and lower extremity edema that appeared in the afternoon and disappeared by the morning. Besides, $33(32,4 \%)$ surveyed patientsindicated periodic heartbeat. In $18(17,7 \%)$ patients sporadic dizziness was observed.

When collecting the history of the disease, it was found that the duration of chronic pancreatitis was $7.00 \pm 3.00$ years, of arterial hypertension $-5.00 \pm 2.00$ years. The frequency of exacerbations of chronic pancreatitis varied from 1 to 4 times a year. Thus, the proportion of patients with exacerbation of chronic pancreatitis 1-2 times a year was $67,6 \%(n=69), 2-3$ times a year $-28,4 \%(n=29), 3-4$ times a year $-5,9 \%(n=6)$. Consequently, it can be stated that the majority of the surveyed contingent had chronic pancreatitis of moderate and mild severity.

Measurement of blood pressure indicated its rise within 1-2 stage. The obtained results of blood pressure and heart rate are presented in Table I.

The level of blood pressure, which was established in the studied patients, corresponded to arterial hypertension of 1-2 stage (the average value of the investigated parameter was $154,15 \pm 9,24 / 94,53 \pm 9,05 \mathrm{~mm} \mathrm{Hg}$ ). As for the the heart rate in the examined patients, it was $80,26 \pm 10,73 \mathrm{bpm}$.

The sudden, acute onset of the disease was indicated by 41 patients $(40,2 \%)$, while the gradual onset with increasing symptoms was recorded in 61 patients (59,8\%). According to our observations, the acute onset of abdomenalgia in patients was accompanied by an increase in blood pressure to higher numbers (170-182 / 101-110 mmHg) compared to patients who had a gradual onset and the level of blood pressure ranged from 150-165 / 93-108 mmHg. A quarter of patients used different self-medication methods (before seeking medical help), but the effect of such therapy was insufficient.

Patients with acute onset sought specialized care within 12-24 hours of the onset of the first symptoms of the disease, but patients with less severe symptoms were hospitalized in 7-14 days after the onset of the disease. In 4 $(3,9 \%)$ patients the complaints mentioned above, started 2-3 months ago, but since the severity of the symptoms was insignificant, they werehopingfor spontaneous recovery. Thus, the leading etiological factor remains the change in the structure of the diet and dietary regimen, but the results of our study confirm that smoking, alcohol, psycho-emo- 
tional load play an important role in the emergence and progression of both diseases. The results obtained are in accordance with the data of scientists who study this problem $[7,8,9]$.

The evaluation of the trophological status of patients with chronic pancreatitis combined with arterial hypertension was based on the body mass index (BMI) calculated using the Kettle formula (developed by AdolpheQuetelet in 1869): $\mathrm{BMI}=$ weight $(\mathrm{kg}) /$ height $(\mathrm{m} 2)$. The results obtained are preseted in Table II.

The results of our studies indicate that the majority of patients ( $\mathrm{n}=48 ; 47,1 \%)$ were overweight, corresponding to a BMI of 25.0 to $29.9 \mathrm{~kg} / \mathrm{m}^{2}$.

\section{DISCUSSION}

In modern research, chronic pancreatitis is considered not only as a combination of local lesions due to the influence of pathochemical inflammatory mechanisms, but as a systemic gastroenterological disease, in the development of which hereditary-constitutional, psychosocial, immunological and psychosomatic mechanisms are involved. It is quite common to have a cohort of patients who have a clear relationship between genesis, disease onset, disease phase, and premorbid features $[1,3]$.The situation is exacerbated by the frequent combination of chronic pancreatitis not only with diseases of the digestive system, but also with cardiovascular diseases, among which, the leading position is occupied by arterial hypertension, since the combination of arterial hypertension and chronic pancreatitis is pathogenically conditioned, primarily through the systemic damage to the vascular system, leading to the development of ischemic effects, activation of the inflammatory component of the disease and metabolic disorders. Features of clinical course of chronic pancreatitis are often determined by its combination with other diseases in the conditions of polymorphism of the modern patient. These combinations, as a rule, contribute to greater torpidity of the clinical course of pancreatitis and often increase the number of complications $[3,5]$, which is clearly observed in our studies. Assessing the symptom of pancreatic pain, interaction between pain intensity and a1-AT concentration and urine diastase level, as well as less reliable effects of lipase, fibrinogen, and serum cortisol levels may be suggested.

\section{CONCLUSIONS}

According to the study data, the negative impact of concomitant hypertension on the clinical course of chronic pancreatitis is established, namely:

- arterial hypertension in most cases causes intensification of pain syndrome;

- pain syndrome in comorbid patients with chronicpancreatitis and arterial hypertension is accompanied by more pronounced manifestations of asthenisation: general weakness, lethargy;

- dependence of the duration of pain syndrome on the height of blood pressure and duration of arterial hypertension is noted;
- dyspepticsyndromeismoreexpressed, variedandprolongedwithhighbloodpressure;

- common etiologic factors in comorbid patients with chronic pancreatitis and arterial hypertensionare smoking $(37,3 \%)$, alcohol $(19,6 \%)$, psycho-emotional overload $(6,9 \%)$;

- BMI results indicate the dominance of excess body mass in most comorbid patients with chronic pancreatitis and arterial hypertension.

\section{REFERENCES}

1. UspenskyYu.P., Pakhomoval.G., BubyakinaV.N.Patohenetycheskoeo bosnovanye perspektyv klynycheskoho yspolzovanyia alhynatsoderzhashcheho preparata Havyskon u patsyentov s khronycheskym pankreatytom, sochetaiushchymsia shastroezofahealnoi refliuksnoi bolezniu [Pathogenetic basing of prospects for clinical use of alginate-containing drug Gaviskon in patients with chronic pancreatitis combined with gastroesophageal reflux disease] Hazeta «Novyny medytsyny ta farmatsii» 2010;7(320). (InRussian)

2. Pakhomova Y.H. Klynyko-psykhosomatycheskye osobennosty y kachestvo zhyzny bolnykh retsydyvyruiushchei formoi khronycheskoho pankreatyta, sochetaiushchehosia s hypertonycheskoi bolezniu [avtoreferat dyssertatsyy]. [Clinico-psychosomatic features and quality of life of patients with recurrent form of chronic pancreatitis, combined with hypertension] SPb.: S.-Peterb. hos. med. akad. ym. Y.Y. Mechnykova; 2003.23 p. (In Russian)

3. Dela Iglesia D, Vallejo-Senra N, López-López Aet al. Pancreatic exocrine insufficiency and cardiovascularris kinpatients with chronic pancreatitis: A prospective, longitudinal cohort study. J Gastroenterol Hepatol. 2019;34(1):277-283. doi: 10.1111/jgh.14460.

4. Viun TY. Klynycheskaia kharakterystyka khronycheskoho pankreatyta u bolnykh s arteryalnoi hypertenzyei. [Clinical characteristics of chronic pancreatitis in patients with hypertension] V: Tez. dokl. VI Mezhdunar. konhr. Kardyolohyia na perekrestke nauk; 2015 Mai 20-22; Tiumen. Tiumen: Fylyal NYY kardyolohyy «Tiumenskyi kardyolohycheskyi tsentr; 2015, p. 53-4.(In Russian)

5. ViunTY, Lazutkyna EA. Arteryalnaia hypertenzyia kak vozmozhnyy faktor formyrovanyia oslozhnenyi u bolnykh khronycheskym pankreatytom. [Arterial hypertension as a possible factor in the formation of complications in patients with chronic pancreatitis.]V: Pasiieshvili LM, holova red. kolehii. Materialy nauk.-prakt. konf. z mizhnar. uchastiu Universytetska klinika: patolohiia sudyn z pozytsii poliprofilnoho pidkhodu; 2018 Berez 16; Kharkiv. Kharkiv: Styl-Izdat; 2018, p. $22-5$. (In Russian)

6. Bonica J.J. The management of pain / Bonica J.J. - Philadelphia : Lea and Febiger, 1990. $-130 \mathrm{p}$.

7. Huberhryts NB, Beliaeva NV, Klochkov AE, Fomenko P. H. Khronycheskyi pankreatyt: rabota nad oshybkamy. [Chronic pancreatitis: working on the mistakes] Suchas. hastroenterlohiia. 2015;(3):97-104.(In Russian)

8. Tretiak SY, Rashchynskyi SM, Rashchynskaia NT, Avdevych DA. Epydemyolohyia y etyolohyia khronycheskoho pankreatyta. [Epidemiology and etiology of chronic pancreatitis] Zdravookhranenye. 2010;(1):15-9. (In Ukrainian)

9. Ferfetska KV. Klinichni osoblyvosti khronichnoho pankreatytu poiednanoho z ozhyrinniam ta tsukrovym diabetom typu 2 . [Clinicalfeatures of chronic pancreatitis combined with obesity and type 2 diabetes.] Bukov. med. visn. 2016:20(1):170-2. (In Ukrainian) 
ORCID and contributionship:

Ksenija I. Chubirko - 0000-0002-4379-0538 A,F

Olesya M. Horlenko - 0000-0002-2210-5503 A,D,F

Tetiana M. Bentsa - 0000-0001-9427-2549E

Mariia A. Derbak - 0000-0003-4791-4080

Adrian I. Tomey - 0000-0002-6095-8937 ${ }^{D}$

Gabriella B. Kossey - 0000-0003-0811-4929

Lyubov Yu. Pushkash - 0000-0003-4651-4608

Valeriya V. Brych-0000-0003-3741-6002 ${ }^{\mathrm{C}}$

Ivan I. Pushkash - 0000-0002-5728-2980

\section{Conflict of interest:}

The Authors declare no conflict of interest.

\section{CORRESPONDING AUTHOR}

Olesya M. Horlenko

Squ. Narodna 2, 88000, Uzhhorod, Ukraine

e-mail: kaf-dithvorob@uzhnu.edu.ua

tel: +380505269658

Received: 17.01 .2020

Accepted: 05.03 .2020

A - Work concept and design, B - Data collection and analysis, C - Responsibility for statistical analysis,

D-Writing the article, $\mathbf{E}$-Critical review, $\mathbf{F}$ - Final approval of the article 